\title{
Preparation and evaluation of a Coated Smectite Clay-based Material Modified with Epichlorohydrin- dimethylamine for the Diclofenac Removal
}

\section{Muhamad Sharafee Shamsudin}

Universiti Sains Malaysia - Engineering Campus Seri Ampangan: Universiti Sains Malaysia - Kampus Kejuruteraan Seri Ampangan

\section{Muhammad Haziq Abdul Taib}

Universiti Sains Malaysia - Engineering Campus Seri Ampangan: Universiti Sains Malaysia - Kampus

Kejuruteraan Seri Ampangan

\section{Syahida Farhan Azha}

Universiti Sains Malaysia - Engineering Campus Seri Ampangan: Universiti Sains Malaysia - Kampus

Kejuruteraan Seri Ampangan

\section{Adrian Bonilla-Petriciolet}

Instituto Tecnológico de Aguascalientes: Instituto Tecnologico de Aguascalientes

\section{Suzylawati Ismail ( $D$ chsuzy@usm.my)}

Science University of Malaysia: Universiti Sains Malaysia

\section{Research Article}

Keywords: Clay-based adsorbent coating, Epichlorohydrin-dimethylamine, Emerging Contaminant, Pharmaceutical waste, Diclofenac, Adsorption

Posted Date: February 23rd, 2022

DOI: https://doi.org/10.21203/rs.3.rs-1332341/v1

License: (c) (i) This work is licensed under a Creative Commons Attribution 4.0 International License. Read Full License 


\section{Abstract}

This study reports the analysis of diclofenac removal from aqueous solution using a novel adsorbent coating. This adsorbent coating was formulated using acrylic polymer emulsion, smectite-based clay powder and epichlorohydrin-dimethylamine in a layer form via the implementation of a facile synthesis method. SEM, EDX and FTIR analysis were carried out for the characterization of this novel adsorbent. The effect of adsorbent composition, diclofenac concentration, temperature and solution $\mathrm{pH}$ on the pharmaceutical removal with adsorbent coating was studied and modeled. Results showed that $303 \mathrm{~K}$ and $\mathrm{pH} 3$ were the best conditions to improve the diclofenac adsorption obtained a adsorption capacity of $25.59 \mathrm{mg} / \mathrm{g}$. Adsorption isotherms and kinetics were quantified and modeled, and the corresponding adsorption mechanism was also analyzed. Diclofenac adsorption with this novel material was exothermic and spontaneous. This alternative adsorbent is promising for diclofenac removal from industrial wastewater systems.

\section{Introduction}

Diclofenac (DCF) is a non-steroidal drug and is classified as a phenylacetic acid with anti-inflammatory, analgesic, and antipyretic properties. DCF in delayed and extended-release forms have been developed to improve its safety profile thus providing application convenience for patients with chronic pains (Altman et al. 2015). The global consumption of DCF in the pharmaceutical industries reaches 940 tons annually (Zhang et al. 2008). Market revenues are also increasing at a record rate over the world, owing to the growth of medicine demand. However, this market condition is associated to the generation of direct pollution problems because the release of pharmaceuticals and their metabolites into the environment, including water, has also increased due to the improper management, treatment, and disposal of these compounds. Pollution caused by pharmaceuticals is now recognized worldwide as a relevant environmental concern that also represents a human health risk. Researchers have looked at the most successful way(s) for removing pharmaceuticals from wastewater to protect the environment (Gadipelly et al. 2014; Pal 2017). However, it is convenient to remark that one limitation is that the types of pharmaceuticals researched in several studies do not reflect the most often produced and consumed pharmaceuticals on the market.

Pharmaceutical wastes are generally discharged to the environment through sewage treatment plant and the improper disposal of expired products, domestic sewage, manufacturing plants waste, hospital waste and runoffs from agricultures (Praveena et al. 2018). The release of the pharmaceutical wastes impacts the environment. In terms of water pollution, the pharmaceutical residue can be released in rivers and groundwater system through surface runoff and leaching. Overall, DCF cannot be removed completely in traditional wastewater treatment plants due to their limited degradation efficiency, which causes the presence of this and other pharmaceuticals in rivers, sediments, sludge and even drinking water sources (Lonappan et al. 2016). Some studies have indicated that DCF can be detected in the concentration range of $0.566-1.48 \mu \mathrm{g} / \mathrm{L}$ (influent) and $0.167-7.01 \mu \mathrm{g} / \mathrm{L}$ (effluent) (Bo et al. 2015). Several countries have also reported the presence of DCF in the wastewater of different industries like India (312 to $360 \mathrm{ng} / \mathrm{L}$ ) 
(Balakrishna et al. 2017), Japan (44 ng/L) (Simazaki et al. 2015), Malaysia (32-5049 ng/L) (Al-Qaim et al. 2015), South Korea (203 $\mu \mathrm{g} / \mathrm{L})$ (Vieno and Sillanpää 2014a), Taiwan (152-185 ng/L) (Fang et al. 2012) and Thailand (367 ng/L) (Tewari et al. 2013). DCF can be also found in sludge, solid waste and soil. For instance, Ashfaq et al. (2017) investigated the concentrations of DCF in a pharmaceutical industry of Pakistan. This study reported diclofenac concentrations of $836 \mu \mathrm{g} / \mathrm{L}, 4968 \mathrm{~g} / \mathrm{kg}, 6632 \mathrm{~g} / \mathrm{kg}$ and $257 \mathrm{~g} / \mathrm{kg}$ for wastewater, sludge, solid waste and soil samples, respectively (Ashfaq et al. 2017). In Malaysia, the mean DCF concentrations were $4.84 \mathrm{ng} / \mathrm{L}, 2.76 \mathrm{ng} / \mathrm{L}$ and $4.30 \mathrm{ng} / \mathrm{L}$ in Gombak, Lui and Selangor rivers (Praveena et al. 2018). However, DCF concentrations up to $188 \mathrm{ng} / \mathrm{L}$ were quantified in Langat river due to the discharge from sewage treatment plants in Langat River Basin (Al-Odaini et al. 2013). These studies highlight the relevance of developing effective removal methods to reduce the DFC environmental pollution.

The low DCF biodegradability often result in a low removal rate during biological waste treatment and only a minor portion of this pharmaceutical can be adsorbed into sludge. In fact, different researchers have highlighted an average reducing rate of 3 to $6 \%$ for DCF depending on the wastewater treatment process (Vieno and Sillanpää, 2014b). Some improvements in wastewater treatment plants have been tried to increase the removal efficiency of this compound but drawbacks in process operation still prevail. For example, the removal of DCF using oxidation processes such as ozonation creates unwanted and toxic by-products, which affects to reach the final purification target (Lonappan et al. 2016). Enzymes could be also used for the complete degradation of DCF from water without the risk of by- product formation. However, it increases the process complexity (Dhiman et al. 2022). Adsorption is an effective and low-cost process for the wastewater treatment and it can outperform other traditional technologies used in the removal of pharmaceutical compounds (Aissaoui et al. 2017; Radjenovic and Petrovic 2017; Ahmadzadeh and Dolatabadi 2018; Hamon et al. 2018; Kurniawan et al. 2018). This technology can produce high-quality water (i.e., with low concentration of pollutants) and its cost-effective tradeoff is better than those reported for other removal methods. Different adsorbents can be applied in the removal of DCF and other pharmaceuticals where activated carbons are the first option due to their wide commercial availability. However, the operational costs involved in the removal treatment system is a current limitation for wastewater purification in several countries and, consequently, it is necessary to develop novel and low-cost adsorbents with improved adsorption properties for pharmaceuticals.

Clay is an excellent choice for the adsorption of water pollutants. They offer several advantages over other low-cost adsorbents. For instance, they are accessible and affordable materials that show an ion exchange capability, chemical stability and large surface area with a variety of structural and surface characteristics (Erdem et al. 2010; Auta and Hameed 2013). Bentonite is a natural inorganic adsorbent with a high montmorillonite concentration that is mainly composed of the clay mineral smectite. In the marine environments, the majority of bentonite is generated through the modification of volcanic ash. This clay is a 2:1 dioctahedral smectite with a sandwiched layer structure consisting of an octahedral alumina layer sandwiched between two tetrahedral silica sheets. Because of the isomorphous substitution of $\mathrm{Si}^{4+}$ in tetrahedral layers by $\mathrm{Al}^{3+}$ and $\mathrm{Al}^{3+}$ in octahedral layers by $\mathrm{Mg}^{2+}$, it has a permanent 
negative charge (Resende et al. 2021). A hydroxyl-aluminosilicate structure underpins the chemical makeup of bentonite (Guo et al. 2019). Bentonite has high surface area and cation exchange capacity besides its ability to the interlamellar expanding (Uddin 2016). The use of bentonite for the removal of cationic compounds is limited due to the presence of a net negative charge surface lattice. Due to the repulsive effect by electrostatic interactions generated by the negative charge on the bentonite surface, it only can adsorb pollutant molecules charged positively (Youssef et al. 2013). Zeta potential of natural bentonite generates its negative charge (Resende et al. 2021). The natural tendency on bentonite is that the zeta potential increases as $\mathrm{pH}$ decreases and this occurs due to the protonation of the hydroxyl groups on the edges of bentonite sheets. However, even the protonation of hydroxyl groups of bentonites is not enough to neutralize all its negative charge. This means that the charge of this clay can remain negative even at acidic $\mathrm{pH}$ conditions.

In this research paper, the authors report the preparation of an adsorbent coating via a simple synthesis procedure and its application in the adsorption of DCF from aqueous solution. This adsorbent coating (ASEC) was obtained from acrylic polymer (APE) as binder, bentonite as additive and epichlorohydrindimethylamine (EPIDMA) as modifier/surfactant. Results showed that the flexible physical characteristics of ASEC provide operational advantages as it is foldable and can be rolled since it has the form of a flat sheet that can be slotted or layered in available limited space in a treatment plant at any condition. ASEC performance for the DCF removal was analyzed at different operating conditions to optimize its application where the impact of EPIDMA dosage, initial concentration, temperature and solution $\mathrm{pH}$ was discussed. Equilibrium and kinetic studies of DCF adsorption were also carried out to calculate relevant parameters of this adsorption system.

\section{Materials And Methods \\ 2.1 Chemicals}

DCF (CAS: 15307-79-6) was supplied by Nano Lite Quest Sdn. Bhd. EPIDMA and APE were purchased from NHA Scientific Resource, Cyberjaya, Malaysia. Smectite-based clay was obtained from Modern Lab Sdn. Bhd. Malaysia. The white cotton cloth was purchased from Kedai Kain 1 Malaysia, Parit Buntar, Malaysia. The $\mathrm{pH}$ of all the solutions was adjusted by sodium hydroxide $(\mathrm{NaOH})$ and hydrochloric acid $(\mathrm{HCl})(0.1 \mathrm{M})$ purchased from Merck, Malaysia. All reagents were used analytical grade and deionized waster was used to prepare the sample coating and DCF solutions.

\subsection{Preparation of ASEC}

The preparation method of ASEC was based on the study by (Azha et al. 2018a). In particular, the clay underwent swelling for $5 \mathrm{~h}$ in deionized water under constant stirring. The bulk clay was then mixed with APE and stirred for $3 \mathrm{~h}$ to form a homogeneous slurry solution. ASEC was formulated using a facile in situ intercalative method with an APE/bulk clay/EPIDMA mass ratio of 1:2:4. Therefore, $2 \mathrm{wt} . \%$ of EPIDMA was then dropped into the APE/clay slurry solution. This slurry was mixed and stirred for $5 \mathrm{~h}$ at room temperature. A strip of $5 \times 20 \mathrm{~cm}$ of cotton cloth was cut and coated with $2 \mathrm{~g}$ of APE/smectite 
clay/EPIDMA using a paint brush on both sides of the strip. This adsorbent was dried at $353 \mathrm{~K}$ in an oven by clipping one end of the strip to the oven rack until its weight reached a constant value. Excess coating in the strip was removed by gently washing with deionized water. The coated strip was finally dried at 353 $\mathrm{K}$ for $2 \mathrm{~h}$. These steps were repeated using 4, 6, 8, 10 and $20 \mathrm{wt}$.\% of EPIDMA dosage to evaluate the impact of ASEC formulation on its physicochemical and adsorption properties. The adsorbent obtained with the best dosage was submitted to characterization and performance evaluation in batch adsorption experiments.

\subsection{Adsorbent characterization}

Morphology of ASEC samples before and after adsorption were analyzed using scanning electron microscope (SEM) with magnifications at 100x, 2000x and 5000x. The elemental composition analysis of ASEC after adsorption was conducted using Energy Dispersive X-ray spectrometry (EDX). Extreme High Resolution Field Emission Scanning Electron Microscope (XHR-FESEM, Model FEI Verios 460L) was also employed to characterize ASEC samples. FTIR spectra were recorded and interpreted to characterize the surface chemistry of ASCE. The pH of point of zero charge (PZC) of ASEC was determined following the procedure reported by (Zulkifli et al. 2019). In particular, $0.1 \mathrm{M}$ sodium chloride solution was prepared and distributed into 7 conical flasks ( $100 \mathrm{~mL}$ each one) where their pHs were adjusted to different values using $\mathrm{HCl}$ and $\mathrm{NaOH}$. ASEC (dimension $110 \mathrm{~mm}$ X $50 \mathrm{~mm}$ ) was immersed into the solution of each conical flask. After that, the change in solution $\mathrm{pH}$ after $48 \mathrm{~h}$ was recorded to determine PZC via the plotting of final $\mathrm{pH}$ versus initial $\mathrm{pH}$.

\subsection{Batch adsorption experiments}

A stock solution of DCF was prepared with $0.1 \mathrm{~g}$ of adsorbate dissolved in $1 \mathrm{~L}$ of distilled water. This stock solution was diluted to obtain different DCF concentrations for the adsorption studies. ASEC strip was introduced inside $250 \mathrm{~mL}$ glass beaker and was clipped on the interior wall to prevent the strip from shifting/moving. Adsorption experiments were performed with $200 \mathrm{~mL}$ of DCF solution that were added into the ASEC strip beaker and stirred at $300 \mathrm{rpm}$ where the solution temperature was regulated and controlled. Preliminary experiments showed that $5 \mathrm{~h}$ were required to get the maximum adsorption capacity of ASEC strip. Batch adsorption studies were performed at different DCF concentration (10 to 50 $\mathrm{mg} / \mathrm{L})$, temperature $(303,318,333$ and $348 \mathrm{~K})$ and $\mathrm{pH}(3,5,7,9$ and 11$)$ where these conditions were selected based in results of other studies (Bhadra et al. 2017; Salaa et al. 2020; Gómez-Avilés et al. 2021; Sharafee Shamsudin et al. 2021). DCF concentration in the aqueous solutions was analysed using UV-vis spectrometer (model Shimadzu UV-1800) with a calibration curve (from 1 to $50 \mathrm{mg} / \mathrm{L}$ ) where the absorbance of samples was measured at wavelength of $276 \mathrm{~nm}$.

The removal efficiency (\%) and adsorption capacity (q, mg/g) were calculated using:

$$
\text { Removalefficiency }(\%)=\frac{C_{o}-C_{f}}{C_{f}} \times 100
$$




$$
q=\frac{\left(C_{O}-C_{f}\right) V}{W}
$$

$$
W=\text { MaSS }_{A S E C}-\text { Mass }_{\text {averagedriedcottoncloth }}
$$

3

where $C_{o}$ and $C_{f}$ are the initial and final concentrations $(\mathrm{mg} / \mathrm{L})$ of $D C F$ in the adsorption experiment, $V$ is volume of DCF solution (L) and W is the ASEC mass $(\mathrm{g})$ used in the removal studies.

\section{Results And Discussion}

\subsection{Synthesis and characterization of ASEC}

The removal efficiency and adsorption capacity of ASEC obtained with different ratios of APE/clay/EPIDMA are shown in Fig. 1. Overall, the DCF removal efficiency of this adsorbent improved when the amount of EPIDMA utilized in the adsorbent preparation also increased. At $2 \mathrm{wt}$ \% of EPIDMA dosage, ASEC was able to achieve a removal efficiency of $42.84 \%$ and its performance increased up to $70.66 \%(26.5 \mathrm{mg} / \mathrm{g})$ at $8 \mathrm{wt} . \%$ of EPIDMA dosage. However, the removal efficiency decreased up to $65.88 \%$ when a EPIDMA dosage higher than 8 wt.\% was used to obtain ASEC. Note that a white precipitate was formed in the solution with an EPIDMA dosage of $20 \mathrm{wt} . \%$. This precipitate was attributed to the breakdown of the ASEC on the cotton strip. In the adsorbent coating, APE showed negative ion properties and was used as a binder for the positively charged bentonite/EPIDMA (Azha et al. 2018c). This breakdown phenomenon was likely due to the negatively charged APE could not bind to the excess positively charged bentonite/EPIDMA in the coating. Therefore, $6 \mathrm{wt}$ \% EPIDMA dosage was chosen as the best value to prepare ASEC for the removal of DCF from the aqueous solution. It is convenient to indicate that this low dosage of EPIDMA for the synthesis procedure contributed to reduce the cost of adsorbent coating production.

SEM images obtained for the analysis of surface morphology of ASEC strip are displayed in Fig. 2. These SEM images were recorded at low (100x), medium (2000x) and high (5000x) magnifications using ASEC samples before and after DCF adsorption. Fig. 2a showed that the weaved hierarchical and linking structure of a spiral cellulose fiber from cotton cloth still can be observed in ASEC even after coating. At $5000 \times$ magnification, it was observed that the coating showed a uniform inhomogeneous structure layering and strongly attached to the adsorbent coating on the cotton cloth. The high magnification SEM image also indicated that the solid particles were distributed on the surface of ASEC strip where it was present in the form of thin layer around the cotton cloth since the weaving structure of the cotton cloth was still visible. SEM images after the DCF adsorption are shown in Fig. $2 d-2 f$ and they demonstrated that the ASEC surface almost maintained its appearance with no noticeable significant changes due to the pharmaceutical loading. 
Results of elemental composition using Energy Dispersive X-ray spectroscopy (EDX) analysis of ASEC strip samples before and after DCF adsorption are summarized in Table 1. The elemental composition analysis indicated the presence of Aluminum (Al), Calcium (Ca), Silica (Si) and Titanium (Ti) in ASEC. These elements were associated to the presence of APE and clay composition of this adsorbent coating where similar results were reported in a previous research of Azha et al. (2018a). The smectite clay was mainly composed of the montmorillonite mineral with other few chemicals like $\mathrm{SiO}_{2}, \mathrm{MgO}, \mathrm{CaO}, \mathrm{Al}_{2} \mathrm{O}_{3}$, $\mathrm{MgO}, \mathrm{K}_{2} \mathrm{O}$, and $\mathrm{Na}_{2} \mathrm{O}$. Notably, the carbon content increased up to 3 times after DCF adsorption. Moreover, the content of sodium (0.04\%) was also evidence to support the adsorption of DCF molecules $\left(\mathrm{C}_{14} \mathrm{H}_{10} \mathrm{C}_{12} \mathrm{NNaO}_{2}\right)$ on ASEC surface.

Table 1

EDX results for the elemental composition of adsorbent coating strip before and after DCF adsorption.

\begin{tabular}{|lll|}
\hline Element & Weight \% & \\
\cline { 2 - 3 } & Before adsorption & After adsorption \\
\hline Carbon, C & 17.99 & 44.55 \\
\hline Oxygen, O & 26.51 & 45.40 \\
\hline Aluminum, Al & 3.03 & 2.11 \\
\hline Silica, Si & 7.02 & 3.14 \\
\hline Chloride, Cl & 1.21 & 0.13 \\
\hline Calcium, Ca & 3.32 & 2.52 \\
\hline Titanium, Ti & 2.77 & 2.11 \\
\hline Sodium, Na & 0.00 & 0.04 \\
\hline
\end{tabular}

FTIR spectra of the prepared pristine bentonite, APE, EPIDMA and ASEC samples before and DCF adsorption are presented in Fig. 3. The broad absorption bands between 3050 and $3550 \mathrm{~cm}^{-1}$, which were present in all samples, were attributable to adsorbed water (H-O-H stretching) (Qian et al. 2007; Kang et al. 2009). The absorption bands of all the samples in the range between $1670 \mathrm{~cm}^{-1}$ to $1760 \mathrm{~cm}^{-1}$ can be attributed to acrylate carbonyl group (Nosrati et al. 2015). Note that APE also contained acrylic and methacrylic additives, which were the prevailing contents of the adsorbent coating sample. The strong and sharp absorption band identified at $1035 \mathrm{~cm}^{-1}$ was due to the Si-O stretching vibration (Selim et al. 2019). The intercalation of EPIDMA polymer within the bentonite interlayer, especially between the silica layers, was also corroborated by the vibration band at $1420 \mathrm{~cm}^{-1}$ (Kang et al. 2009; Qian et al. 2010). Furthermore, the absorption bands of stretching of SiO, AlO and $\mathrm{MgO}$ were identified at 1030, 860 and $800 \mathrm{~cm}^{-1}$, respectively. The chemical composition of APE and the silicate structure of bentonite generated these bands (Qian et al. 2010). C=C vibrations in aromatic rings were associated to the absorption band between 1500 and $1600 \mathrm{~cm}^{-1}$, as well as the band between 1450 and $1500 \mathrm{~cm}^{-1}$. In the samples analyzed 
after the pharmaceutical adsorption, this band was also linked to the existence of DCF molecules on ASEC surface.

\subsection{Impact of operating conditions on the performance of ASEC for DCF adsorption}

The effect of DCF concentration on the removal performance of ASEC was studied at 10 to $50 \mathrm{mg} / \mathrm{L}$ where the other operating parameters were fixed at constant values (i.e., 6 wt.\% of EPIDMA dosage for the adsorbent coating, $\mathrm{pH} 3,303 \mathrm{~K}$ and $6 \mathrm{~h}$ of contact time). Results of these studies are reported in Fig. 4. It was observed that the adsorption capacity increased from 4.74 to $22.4 \mathrm{mg} / \mathrm{g}$ as the DCF concentration increased from 10 to $50 \mathrm{mg} / \mathrm{L}$. These experimental results showed that the adsorption rate was linearly proportional to DCF concentration. At the initial stage, the adsorption rate was rapid due to the availability of a large number of vacant functional groups on ASEC surface (Dutta et al. 2015; Shamsudin et al. (2021). Note that the adsorbate concentration in the aqueous solution was directly related to the driving force at the solid-liquid interface and its increment enhanced the mass transfer rate thus improving the corresponding adsorption capacities (Hameed et al. 2008; Ngakou et al. 2019). The increments of DCF concentration generated gradually the adsorbent saturation caused by a reduction in the number of available active sites for DCF adsorption.

Four different solution temperature (i.e., 303, 318, 333 and $348 \mathrm{~K}$ ) were selected to study the effect of temperature on DCF adsorption with ASEC. These tests were done using DCF initial concentrations from 10 to $50 \mathrm{mg} / \mathrm{L}$ and results are reported in Fig. 5. In the adsorption process, the solution temperature plays an important role to determine the adsorbent performance as well as allows to confirm the thermodynamic nature of the separation. Fig. 5 showed that the DCF adsorption capacities decreased from 24.1 to $4.9 \mathrm{mg} / \mathrm{g}$ when the solution temperature changed from 303 to $348 \mathrm{~K}$. It was concluded that this adsorption process was exothermic where the DCF removal was more favorable at low temperature. This phenomenon happened due to the high temperature affected the physical bonding between the adsorbate molecules and active sites of ASEC surface, thus leading to the reduction of adsorption capacity. The desorption rate of adsorbate molecules from ASEC surface increased with solution temperature thus resulting in a low removal efficiency. This phenomenon occurred due to the weakening of the interaction between adsorbate molecules and ASEC functional groups (Dutta et al. 2015). Therefore, $303 \mathrm{~K}$ was the best temperature to favor the removal of DCF with ASEC.

Figure 6 shows that the solution $\mathrm{pH}$ displayed an important effect on the DCF adsorption properties of ASEC. Note that the $\mathrm{pH}$ can alter the surface charge of this adsorbent and the dissociation of its surface functional groups besides it also impacts the ionization degree and solubility of adsorbate molecules. DCF adsorption capacities of ASEC decreased from 25.59 to $12.40 \mathrm{mg} / \mathrm{g}$ in the $\mathrm{pH}$ range of 3 to 11 . The efficiency removal also decreased from 77.05 to $38.53 \%$ due to the $\mathrm{pH}$ increment. These results indicated that $\mathrm{pH} 3$ was the best value for DCF adsorption thus obtaining $77.05 \%$ removal and an adsorption capacity of $25.59 \mathrm{mg} / \mathrm{g}$ for a $50 \mathrm{mg} / \mathrm{L}$ initial concentration. Note that DCF has $p K a=4.0$ and this adsorbate is present mainly in its neutral form at $\mathrm{pH} 3<p K a$ where its solubility in water also decreases. 
DCF molecule contains two aromatic rings and this adsorbate shows a negative surface charge due to the ionization process at $\mathrm{pH}<p K a$ (Dutta et al. 2015), thus explaining the reduction of DCF adsorption capacities at alkaline conditions that favored the presence of repulsive electrostatic forces with the ASEC surface (De Oliveira et al. 2017). PZC of ASEC was 7.54 and, consequently, ASEC was positively charged at solution pH < PZC (Çalişkan and Göktürk 2010). At acidic solutions, the presence of electrostatic interactions and van der Waals forces were expected to be responsible for the adsorption of DCF molecules on ASEC surface (Ayawei et al. 2017).

Langmuir and Freundlich isotherm models were chosen to fit the experimental equilibrium data and results are reported in Table 2. Overall, the Freundlich model was the best to fit the experimental DCF adsorption data thus obtaining the highest $R^{2}(0.89-0.99)$ and lowest ARE values $(0.20$ to 2.52$)$.

Therefore, this adsorption process occurred in the heterogeneous surface of ASEC and was not limited by one-layer formation. The calculated values of parameter $n$ were between 0 and 1 thus indicating that DCF adsorption on ASEC was favorable (Maia et al. 2019).

Table 2

Results of isotherm modeling for the DCF adsorption on ASEC.

\begin{tabular}{|lllll|}
\hline Parameter & \multicolumn{4}{c}{ Temperature (K) } \\
\cline { 2 - 5 } & $\mathbf{3 0 3}$ & $\mathbf{3 1 8}$ & 333 & 348 \\
\hline \multicolumn{4}{|c|}{ Langmuir isotherm } \\
\hline $\mathrm{q}_{\max }(\mathrm{mg} / \mathrm{g})$ & 4253.3 & 8455.5 & 12477 & 3774.6 \\
\hline $\mathrm{K}_{\mathrm{L}}(\mathrm{L} / \mathrm{mg})$ & 0.0003 & 0.00007 & 0.0001 & 0.00003 \\
\hline $\mathrm{R}^{2}$ & 0.9082 & 0.9470 & 0.8641 & 0.7964 \\
\hline $\mathrm{ARE}$ & 1.0404 & 0.9624 & 2.9714 & 5.5637 \\
\hline Freundlich isotherm & & & \\
\hline $1 / n$ & 1.4620 & 1.2986 & 1.4628 & 1.5136 \\
\hline $\mathrm{n}$ & 0.6839 & 0.7701 & 0.6836 & 0.6607 \\
\hline $\mathrm{K}_{\mathrm{F}}(\mathrm{L} / \mathrm{mg})^{1 / n}$ & 0.3865 & 0.2324 & 0.0728 & 0.0195 \\
\hline $\mathrm{R}^{2}$ & 0.9875 & 0.9926 & 0.9693 & 0.8912 \\
\hline ARE & 0.3991 & 0.1955 & 0.9319 & 2.5242 \\
\hline
\end{tabular}

The analysis of adsorption kinetics contributes with the calculation of parameters required for the fullscale design of an adsorption system. Experimental data of DCF adsorption on ASEC were analyzed with the pseudo-first and pseudo-second order models. Table 3 reports the results of kinetic modeling. The calculated equilibrium adsorption capacities, ARE and $\mathrm{R}^{2}$ of the pseudo-second order model were better 
than those values obtained with the pseudo-first order equation. It could be expected that the DCF adsorption rate on ASEC was controlled by chemisorption mechanism where hydrogen bonding and electrostatic forces played a relevant role (Ferreira et al. 2015)

Table 3

Results of kinetic modeling of the DCF adsorption on ASEC at $303 \mathrm{~K}$ and pH 3 .

\begin{tabular}{|c|c|c|c|c|c|c|c|c|c|}
\hline \multirow{2}{*}{$\begin{array}{l}\text { Co } \\
\text { (mg/L) }\end{array}$} & \multirow{2}{*}{$\begin{array}{l}q_{e, \exp } \\
(\mathrm{mg} / \mathrm{g})\end{array}$} & \multicolumn{4}{|c|}{ Pseudo-first order } & \multicolumn{4}{|c|}{ Pseudo-second order } \\
\hline & & $\mathrm{R}^{2}$ & $\begin{array}{l}k_{1} \\
(1 / h)\end{array}$ & $\begin{array}{l}q_{e, c a l} \\
(\mathrm{mg} / \mathrm{g})\end{array}$ & ARE & $\mathrm{R}^{2}$ & $\begin{array}{l}\mathrm{k}_{2} \\
(\mathrm{~g} / \mathrm{mg} \cdot \mathrm{h})\end{array}$ & $\begin{array}{l}\mathrm{q}_{\mathrm{e}, \mathrm{cal}} \\
(\mathrm{mg} / \mathrm{g})\end{array}$ & ARE \\
\hline 10 & 4.737 & 0.937 & 1.374 & 4.739 & 0.834 & 0.992 & 0.663 & 4.498 & 0.245 \\
\hline 20 & 9.597 & 0.994 & 2.282 & 9.595 & 0.221 & 0.991 & 0.674 & 9.356 & 0.261 \\
\hline 30 & 12.93 & 0.986 & 2.547 & 12.85 & 0.314 & 0.997 & 0.556 & 12.93 & 0.134 \\
\hline 40 & 18.97 & 0.945 & 1.950 & 18.60 & 0.695 & 0.992 & 0.245 & 18.33 & 0.238 \\
\hline 50 & 22.40 & 0.930 & 2.209 & 22.13 & 0.755 & 0.982 & 0.233 & 21.71 & 0.370 \\
\hline
\end{tabular}

Thermodynamic parameters of the adsorption of DCF molecules on ASEC were calculated using the van't Hoff approach, see Table 4. Adsorption enthalpy $(\Delta \mathrm{H} \mathbb{\nabla})$ was $-58.66 \mathrm{~kJ} / \mathrm{mol}$ thus confirming the exothermic removal of this pharmaceutical. Note that this enthalpy value indicated the presence of both physical and chemical interactions during DCF adsorption (Dutta et al. 2015). The calculated positive value of adsorption entropy $(\Delta S \nabla=0.09 \mathrm{~kJ} / \mathrm{mol} \cdot \mathrm{K})$ suggested some structural changes or readjustments in the adsorbate-adsorbent complex, while the negative values of $\Delta \mathrm{G} \otimes$ confirmed that this adsorption process was thermodynamically spontaneous.

Table 4

Thermodynamic parameters for the DCF adsorption on ASEC.

\begin{tabular}{|ll|}
\hline $\mathbf{T}(\mathrm{K})$ & $\boldsymbol{\Delta} \mathbf{G}^{\circ}(\mathrm{kJ} / \mathrm{mol})$ \\
\hline 303 & -87.15 \\
\hline 313 & -88.56 \\
\hline 323 & -89.97 \\
\hline 333 & -91.38 \\
\hline
\end{tabular}

\subsection{Mechanism of DCF adsorption on ASEC}

The mechanism of adsorption of DCF molecules on the ASEC surface involved a variety of interactions like hydrogen bonding, electrostatic attraction, $\pi-\pi$ stacking interaction, hydrophobic reaction, chemical surface complexation and van der Waals forces (Yu et al. 2017; Li et al. 2018). Note that APE derived from methacrylic ester, acrylic and their derivatives can be considered as a promising material to prepare 
adsorbent coatings for water treatment because it has excellent mechanical properties and a net negative surface charge. The anionic property of APE is attributed by the inclusion of $\mathrm{Al}_{2} \mathrm{O}_{3}, \mathrm{SiO}_{2}, \mathrm{TiO}_{2}$, and $\mathrm{CaO}$ as major constituents. Therefore, APE contributed to the adsorption properties of cationic particles and also acted as a binder to be coated onto the substrate. The intercalation of EPIDMA molecules with the clay increased the hydrophobic property, which resulted in the development of a positively charged surface of ASEC. For illustration, Fig. 7 describes the adsorption mechanism of DCF molecules on ASEC at $\mathrm{pH}<$ $\mathrm{pKa}$. At this operating condition, the hydrogen bonding could be a relevant force involved in the adsorption of DCF on ASEC surface. In particular, this hydrogen bonding was generated by the electronegative species in DCF (e.g., $\mathrm{O}$ and $\mathrm{N}$ ) and the hydroxyl group of ASEC. On the other hand, the attachment of EPIDMA to aluminosilicate of bentonite produced a positive charge on ASEC surface where $\mathrm{PZC}>\mathrm{pH}$. Electrostatic forces could be relevant for the removal of anionic charged pollutants and hydrocarbons from wastewater due to their affinity to the positively charged ASEC surface. Similar studies conducted by (Liang et al. 2019; Tam et al. 2020) also concluded the relevance of hydrogen bonding on the DCF adsorption at $\mathrm{pH}<\mathrm{pKa}$. As stated by (Tam et al. 2020), the DCF removal decreased at $\mathrm{pH}>6.5$ due to the electrostatic repulsive interaction between the deprotonated carboxylic acid group of this pharmaceutical and the negatively charged adsorbent surface.

\section{Conclusions}

A novel APE/smectite clay/EPIDMA coating was prepared via a simple preparation method and used to remove diclofenac from aqueous solution. The surface morphology of this adsorbent demonstrated the condition of coating onto the surface of the cotton cloth. The removal efficiency of this pharmaceutical with this adsorbent depended on the EPIDMA dosage, DCF concentration, temperature and solution $\mathrm{pH}$. It was found that 6 wt.\% of EPIDMA dosage was the best composition to improve the adsorption properties of this adsorbent and to reduce its cost of production. The best operating conditions for diclofenac removal was $303 \mathrm{~K}$ and pH 3 to obtain an adsorption capacity of $25.59 \mathrm{mg} / \mathrm{g}$. Diclofenac adsorption with this novel material was exothermic and caused by both physical and chemical forces where hydrogen bonding and electrostatic interactions played a relevant role in the removal mechanism. In summary, this novel material is promising and has a wide range of possible applications in the water treatment of industrial sector.

\section{Declarations}

\section{Acknowledgement}

The authors acknowledge the Ministry of Higher Education Malaysia for Fundamental Research Grant Scheme with Project Code FRGS/1/2018/TK02/USM/02/6.

\section{Availability of data and materials}

Not applicable 
All authors have given approval to the final version of the paper. Muhamad Sharafee Shamsudin performed experimental, conceptual, calculation, and manuscript writing; Muhammad Haziq Abdul Taib assisted experimental work and manuscript; Syahida Farhan Azha and Adrian Bonilla-Petriciolet carried out manuscript interpretation and correction; Suzylawati Ismail carried out supervision.

\section{Ethical approval}

Not applicable. This manuscript does not involve researching about humans and animals.

\section{Consent to participate}

All of the authors consented to participate in the drafting of the manuscript

\section{Consent for publication}

All the authors consented to publish this manuscript

\section{Conflict of interest}

The authors declare no competing interest.

\section{References}

1. Ahmadzadeh S, Dolatabadi M (2018) Removal of acetaminophen from hospital wastewater using electro-Fenton process. Environ Earth Sci 77:1-11. https://doi.org/10.1007/s12665-017-7203-7

2. Aissaoui S, Ouled-Haddar H, Sifour M et al (2017) Biological Removal of the Mixed Pharmaceuticals: Diclofenac, Ibuprofen, and Sulfamethoxazole Using a Bacterial Consortium. Iran J Biotechnol 15:135-142. https://doi.org/10.15171/ijb.1530

3. Al-Odaini NA, Zakaria MP, Yaziz MI et al (2013) The occurrence of human pharmaceuticals in wastewater effluents and surface water of Langat River and its tributaries, Malaysia. Int J Environ Anal Chem 93:245-264. https://doi.org/10.1080/03067319.2011.592949

4. Al-Qaim FF, Abdullah MP, Othman MR et al (2015) Investigation of the environmental transport of human pharmaceuticals to surface water: A case study of persistence of pharmaceuticals in effluent of sewage treatment plants and hospitals in Malaysia. J Braz Chem Soc 26:1124-1135. https://doi.org/10.5935/0103-5053.20150075

5. Altman R, Bosch B, Brune K et al (2015) Advances in NSAID development: Evolution of diclofenac products using pharmaceutical technology. Drugs 75:859-877. https://doi.org/10.1007/s40265-0150392-z

6. Ashfaq M, Nawaz Khan K, Saif Ur Rehman M et al (2017) Ecological risk assessment of pharmaceuticals in the receiving environment of pharmaceutical wastewater in Pakistan. Ecotoxicol Environ Saf 136:31-39. https://doi.org/10.1016/j.ecoenv.2016.10.029 
7. Auta M, Hameed BH (2013) Acid modified local clay beads as effective low-cost adsorbent for dynamic adsorption of methylene blue. J Ind Eng Chem 19:1153-1161. https://doi.org/10.1016/j.jiec.2012.12.012

8. Ayawei N, Ebelegi AN, Wankasi D (2017) Modelling and Interpretation of Adsorption Isotherms. 2017

9. Azha SF, Sellaoui L, Shamsudin MS et al (2018a) Synthesis and characterization of a novel amphoteric adsorbent coating for anionic and cationic dyes adsorption: Experimental investigation and statistical physics modelling. Chem Eng J. https://doi.org/10.1016/j.cej.2018.06.092. 351:

10. Azha SF, Sellaoui L, Shamsudin MS et al (2018b) Synthesis and characterization of a novel amphoteric adsorbent coating for anionic and cationic dyes adsorption: Experimental investigation and statistical physics modelling. Chem Eng J 351:221-229.

https://doi.org/10.1016/j.cej.2018.06.092

11. Azha SF, Sharafee M, Shahadat M (2018c) Low cost zwitterionic adsorbent coating for treatment of anionic and cationic dyes. J Ind Eng Chem 67:187-198. https://doi.org/10.1016/j.jiec.2018.06.029

12. Balakrishna K, Rath A, Praveenkumarreddy $Y$ et al (2017) A review of the occurrence of pharmaceuticals and personal care products in Indian water bodies. Ecotoxicol Environ Saf 137:113-120. https://doi.org/10.1016/j.ecoenv.2016.11.014

13. Bhadra BN, Ahmed I, Kim S, Jhung SH (2017) Adsorptive removal of ibuprofen and diclofenac from water using metal-organic framework-derived porous carbon. Chem Eng J 314:50-58. https://doi.org/10.1016/j.cej.2016.12.127

14. Bo L, Feng L, Fu J et al (2015) The fate of typical pharmaceuticals in wastewater treatment plants of Xi'an city in China. J Environ Chem Eng 3:2203-2211. https://doi.org/10.1016/j.jece.2015.08.001

15. Çalişkan E, Göktürk S (2010) Adsorption characteristics of sulfamethoxazole and metronidazole on activated carbon. Sep Sci Technol 45:244-255. https://doi.org/10.1080/01496390903409419

16. De Oliveira T, Guégan R, Thiebault T et al (2017) Adsorption of diclofenac onto organoclays: Effects of surfactant and environmental ( $\mathrm{pH}$ and temperature) conditions. J Hazard Mater 323:558-566. https://doi.org/10.1016/j.jhazmat.2016.05.001

17. Dhiman N, Chaudhary S, Singh A, Chauhan A (2022) Sustainable degradation of pharmaceutical waste using different fungal strains: Enzyme induction, kinetics and isotherm studies. Environ Technol Innov 25:102156. https://doi.org/10.1016/j.eti.2021.102156

18. Dutta M, Das U, Mondal S (2015) Adsorption of acetaminophen by using tea waste derived activated carbon. Int J Environ Sci 6:270-281. https://doi.org/10.6088/ijes.6031

19. Erdem B, Özcan A, Özcan AS (2010) Adsorption and solid phase extraction of 8-hydroxyquinoline from aqueous solutions by using natural bentonite. Appl Surf Sci 256:5422-5427. https://doi.org/https://doi.org/10.1016/j.apsusc.2009.12.126

20. Fang TH, Nan FH, Chin TS, Feng HM (2012) The occurrence and distribution of pharmaceutical compounds in the effluents of a major sewage treatment plant in Northern Taiwan and the receiving coastal waters. Mar Pollut Bull 64:1435-1444. https://doi.org/10.1016/j.marpolbul.2012.04.008 
21. Ferreira RC, Lima HHC, De, Cândido AA et al (2015) Adsorption of Paracetamol Using Activated Carbon of Dende and Babassu Coconut Mesocarp. 9:717-722

22. Gadipelly C, Pérez-gonzález A, Yadav GD, PHARMACEUTICAL INDUSTRY WASTE WATER: REVIEW OF THE TECHNOLOGIES FOR WATER TREATMENT AND REUSE (2014) Ind Eng Chem Res 53:1157111592. https://doi.org/https://doi.org/10.1021/ie501210j

23. Gómez-Avilés A, Sellaoui L, Badawi M et al (2021) Simultaneous adsorption of acetaminophen, diclofenac and tetracycline by organo-sepiolite: Experiments and statistical physics modelling. Chem Eng J 404. https://doi.org/10.1016/j.cej.2020.126601

24. Guo W, Xia T, Pei M et al (2019) Bentonite modified by allylamine polymer for adsorption of amido black 10B. Polymers (Basel) 11:. https://doi.org/10.3390/polym11030502

25. Hameed BH, Chin LH, Rengaraj S (2008) Adsorption of 4-chlorophenol onto activated carbon prepared from rattan sawdust. Desalination 225:185-198. https://doi.org/https://doi.org/10.1016/j.desal.2007.04.095

26. Hamon P, Moulin P, Ercolei L, Marrot B (2018) Oncological ward wastewater treatment by membrane bioreactor: Acclimation feasibility and pharmaceuticals removal performances. J Water Process Eng 21:9-26. https://doi.org/10.1016/j.jwpe.2017.11.012

27. Kang Q, Zhou W, Li Q et al (2009) Adsorption of anionic dyes on poly(epicholorohydrin dimethylamine) modified bentonite in single and mixed dye solutions. Appl Clay Sci 45:280-287. https://doi.org/10.1016/j.clay.2009.06.010

28. Kurniawan TA, Yanyan L, Ouyang T et al (2018) BaTiO3/TiO2composite-assisted photocatalytic degradation for removal of acetaminophen from synthetic wastewater under UV-vis irradiation. Mater Sci Semicond Process 73:42-50. https://doi.org/10.1016/j.mssp.2017.06.048

29. Li X, Liu Y, Zhang C et al (2018) Porous Fe2O3 microcubes derived from metal organic frameworks for efficient elimination of organic pollutants and heavy metal ions. Chem Eng J 336:241-252. https://doi.org/10.1016/j.cej.2017.11.188

30. Liang XX, Omer AM, Hu Z et al (2019) Efficient adsorption of diclofenac sodium from aqueous solutions using magnetic amine-functionalized chitosan. Chemosphere 217:270-278. https://doi.org/10.1016/j.chemosphere.2018.11.023

31. Lonappan L, Brar SK, Das RK et al (2016) Diclofenac and its transformation products: Environmental occurrence and toxicity - A review. Environ Int 96:127-138.

https://doi.org/10.1016/j.envint.2016.09.014

32. Maia GS, de Andrade JR, da Silva MGC, Vieira MGA (2019) Adsorption of diclofenac sodium onto commercial organoclay: Kinetic, equilibrium and thermodynamic study. Powder Technol 345:140150. https://doi.org/10.1016/j.powtec.2018.12.097

33. Ngakou CS, Anagho GS, Ngomo HM (2019) Non-linear Regression Analysis for the Adsorption Kinetics and Equilibrium Isotherm of Phenacetin onto Activated Carbons. Curr J Appl Sci Technol 36:1-18. https://doi.org/10.9734/cjast/2019/v36i430246 
34. Nosrati R, Olad A, Nofouzi K (2015) A self-cleaning coating based on commercial grade polyacrylic latex modified by TiO2/Ag-exchanged-zeolite-A nanocomposite. Appl Surf Sci 346:543-553. https://doi.org/10.1016/j.apsusc.2015.04.056

35. Pal P (2017) Treatment and Disposal of Pharmaceutical Wastewater: Towards Sustainable Strategy. Sep Purif Rev 2119:179-198. https://doi.org/10.1080/15422119.2017.1354888

36. Praveena SM, Shaifuddin SNM, Sukiman S et al (2018) Pharmaceuticals residues in selected tropical surface water bodies from Selangor (Malaysia): Occurrence and potential risk assessments. Sci Total Environ 642:230-240. https://doi.org/10.1016/j.scitotenv.2018.06.058

37. Qian L, Yue Q-Y, Sun H-J et al (2010) A comparative study on the properties, mechanisms and process designs for the adsorption of non-ionic or anionic dyes onto cationic-polymer/bentonite. $J$ Environ Manage 91:1601-1611. https://doi.org/10.1016/j.jenvman.2010.03.001

38. Qian L, Yue QY, Su Y et al (2007) Cationic polyelectrolyte/bentonite prepared by ultrasonic technique and its use as adsorbent for Reactive Blue K-GL dye. J Hazard Mater 147:370-380. https://doi.org/10.1016/j.jhazmat.2007.01.024

39. Radjenovic J, Petrovic M (2017) Removal of sulfamethoxazole by electrochemically activated sulfate: Implications of chloride addition. J Hazard Mater 333:242-249. https://doi.org/10.1016/j.jhazmat.2017.03.040

40. Resende RF, Silva TFB, Santos NA do et al (2021) Anionic collector adsorption onto bentonites and potential applications in the treatment of mining wastewater. Colloids Surf Physicochem Eng Asp 629:127401. https://doi.org/10.1016/j.colsurfa.2021.127401

41. Salaa F, Bendenia S, Lecomte-Nana GL, Khelifa A (2020) Enhanced removal of diclofenac by an organohalloysite intercalated via a novel route: Performance and mechanism. Chem Eng J 396. https://doi.org/10.1016/j.cej.2020.125226

42. Selim AQ, Sellaoui L, Mobarak M (2019) Statistical physics modelling of phosphate adsorption onto chemically modified carbonaceous clay. J Mol Liq. https://doi.org/10.1016/j.molliq.2019.01.100

43. Sharafee Shamsudin M, Farhan Azha S, Lotfi Sellaoui et al (2021) Performance and interactions of diclofenac adsorption using Alginate/Carbon-based Films: Experimental investigation and statistical physics modelling. Chem Eng J 428:131929. https://doi.org/10.1016/j.cej.2021.131929

44. Simazaki D, Kubota R, Suzuki T et al (2015) Occurrence of selected pharmaceuticals at drinking water purification plants in Japan and implications for human health. Water Res 76:187-200. https://doi.org/10.1016/j.watres.2015.02.059

45. Tam NTM, Liu Y, Bashir H et al (2020) Efficient removal of diclofenac from aqueous solution by potassium ferrate-activated porous graphitic biochar: Ambient condition influences and adsorption mechanism. Int J Environ Res Public Health 17:1-22. https://doi.org/10.3390/ijerph17010291

46. Tewari S, Jindal R, Kho YL et al (2013) Major pharmaceutical residues in wastewater treatment plants and receiving waters in Bangkok, Thailand, and associated ecological risks. Chemosphere 91:697-704. https://doi.org/10.1016/j.chemosphere.2012.12.042

47. Uddin F (2016) Montmorillonite: An Introduction to Properties and Utilization 
48. Vieno N, Sillanpää M (2014a) Fate of diclofenac in municipal wastewater treatment plant - A review. Environ Int 69:28-39. https://doi.org/10.1016/j.envint.2014.03.021

49. Vieno N, Sillanpää M (2014b) Fate of diclofenac in municipal wastewater treatment plant - A review. Environ Int 69:28-39. https://doi.org/10.1016/j.envint.2014.03.021

50. Youssef AM, AkI M, Al-Awadhi MM (2013) Adsorption of Acid Dyes onto Bentonite and Surfactantmodified Bentonite. J Anal Bioanal Tech 04. https://doi.org/10.4172/2155-9872.1000174

51. Yu S, Wang X, Chen Z et al (2017) Layered double hydroxide intercalated with aromatic acid anions for the efficient capture of aniline from aqueous solution. J Hazard Mater 321:111-120. https://doi.org/10.1016/j.jhazmat.2016.09.009

52. Zhang Y, Geißen SU, Gal C (2008) Carbamazepine and diclofenac: Removal in wastewater treatment plants and occurrence in water bodies. Chemosphere 73:1151-1161.

https://doi.org/10.1016/j.chemosphere.2008.07.086

53. Zulkifli MA, Afandi A, Din ATM (2019) Preliminary study on the synthesis of granular ordered mesoporous carbon - montmorillonite composite adsorbents for removal of water pollutants Preliminary Study on the Synthesis of Granular Ordered Mesoporous Carbon - Montmorillonite Composite Adsorbents. AIP Conf Proc 2124020026. https://doi.org/https://doi.org/10.1063/1.5117086

\section{Figures}

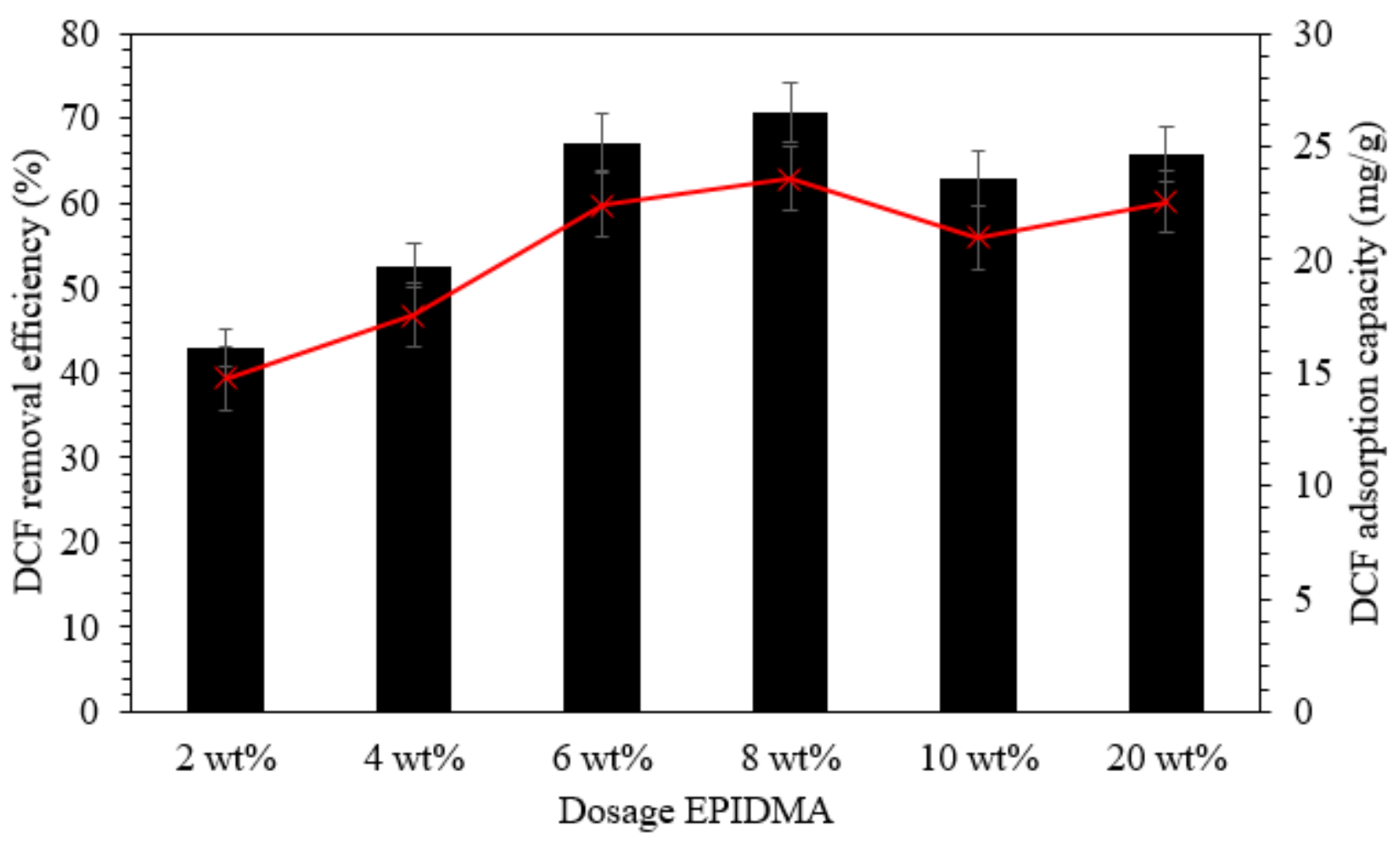

Removal $(\%) \quad *$ Adsorption capacity $(\mathrm{mg} / \mathrm{g})$ 
Figure 1

DCF removal efficiency and adsorption capacities of ASEC obtained with different EPIDMA dosages.
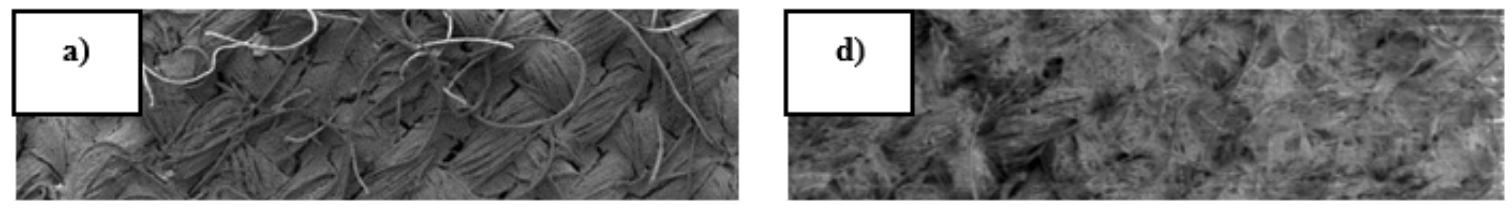

Figure 2 
SEM images of ASEC $(a, b, c)$ before and $(d, e, f)$ after DCF adsorption.

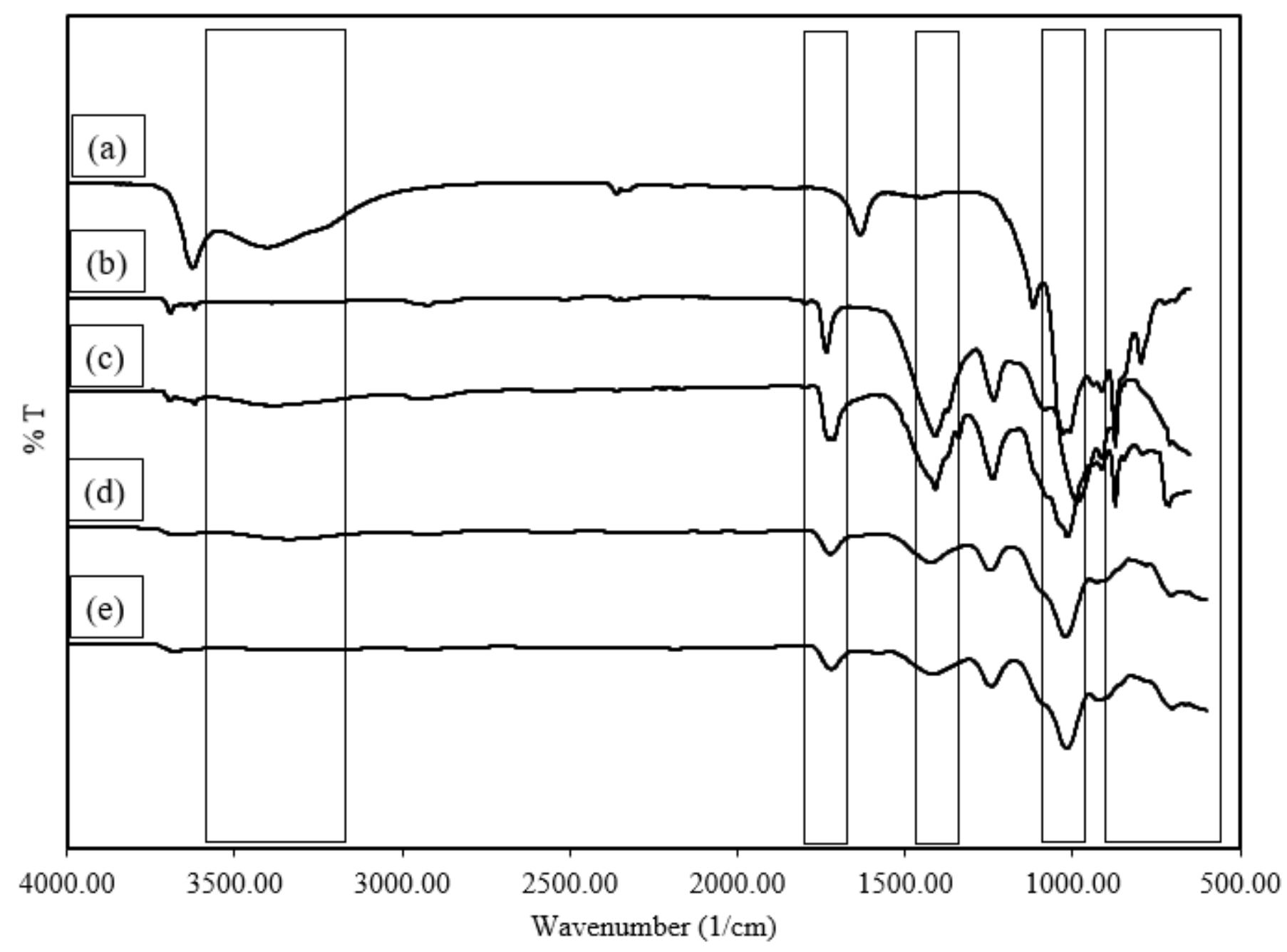

Figure 3

FTIR spectra of a) smectite clay, b) APE, c) EPIDMA, d) raw ASEC and e) ASEC loaded with DCF. 


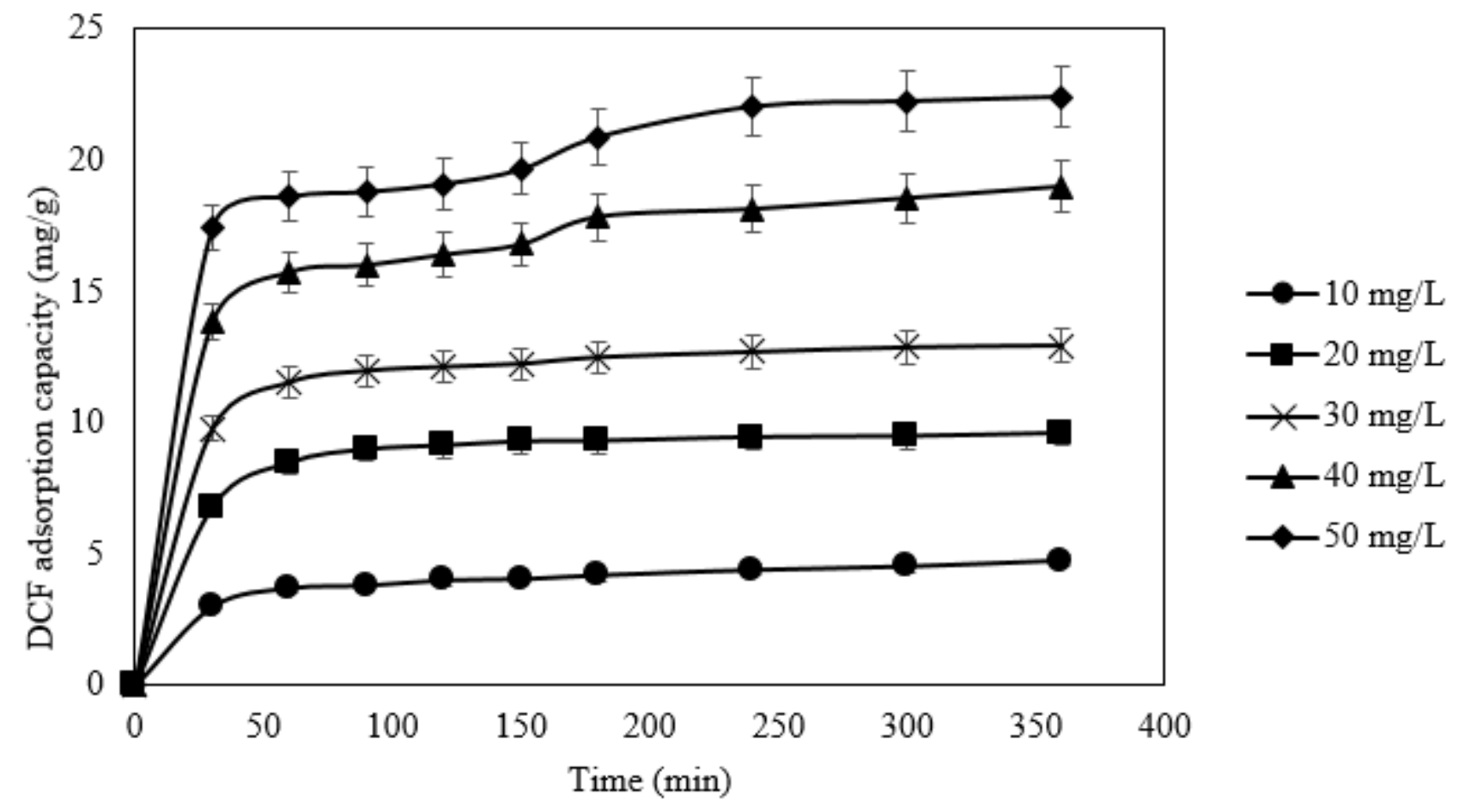

Figure 4

Kinetics of the DCF adsorption on ASEC at pH 3, $303 \mathrm{~K}$ and $300 \mathrm{rpm}$. 


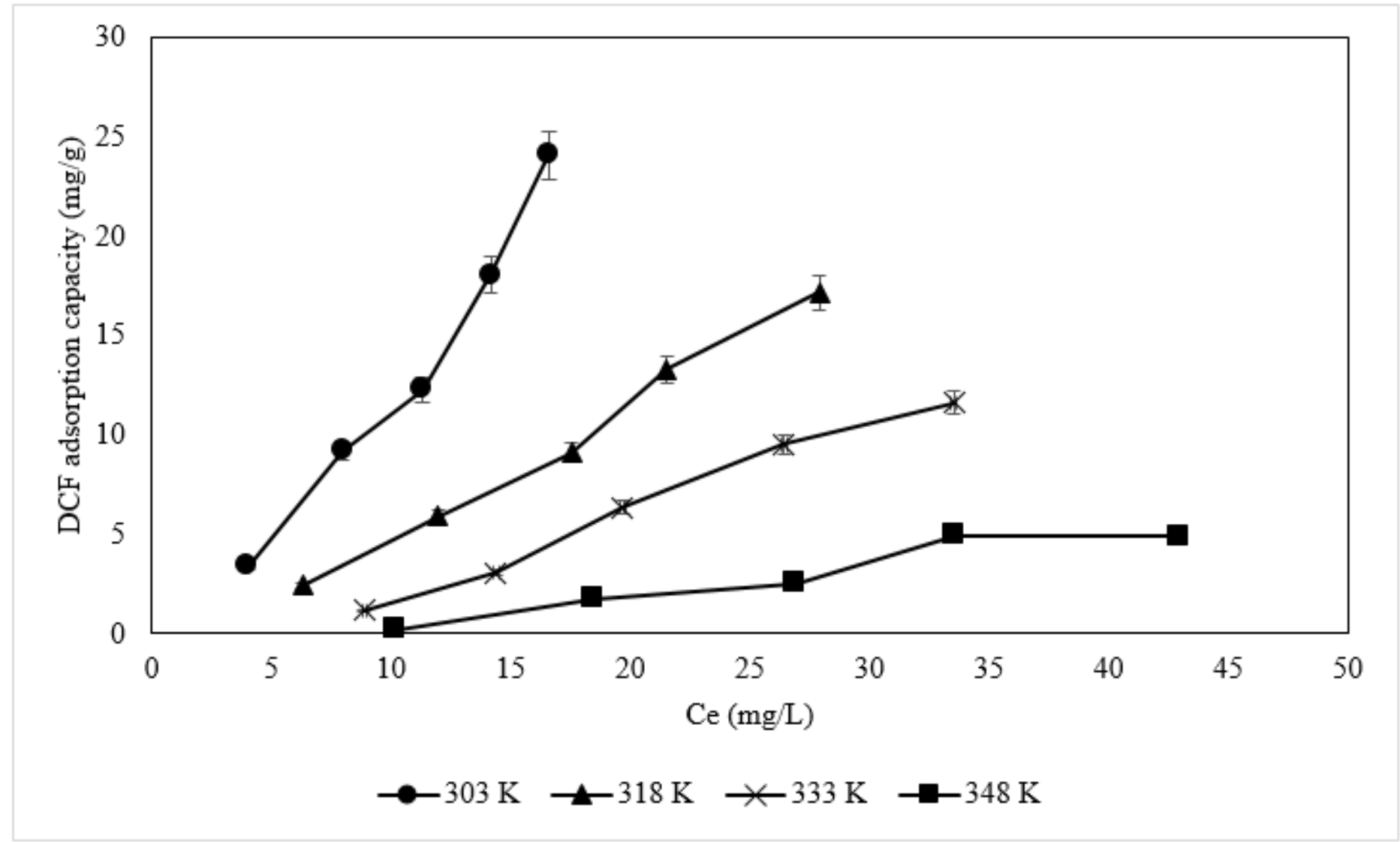

Figure 5

Isotherms of the DCF adsorption on ASEC at different temperatures, $\mathrm{pH} 3$ and $300 \mathrm{rpm}$. 


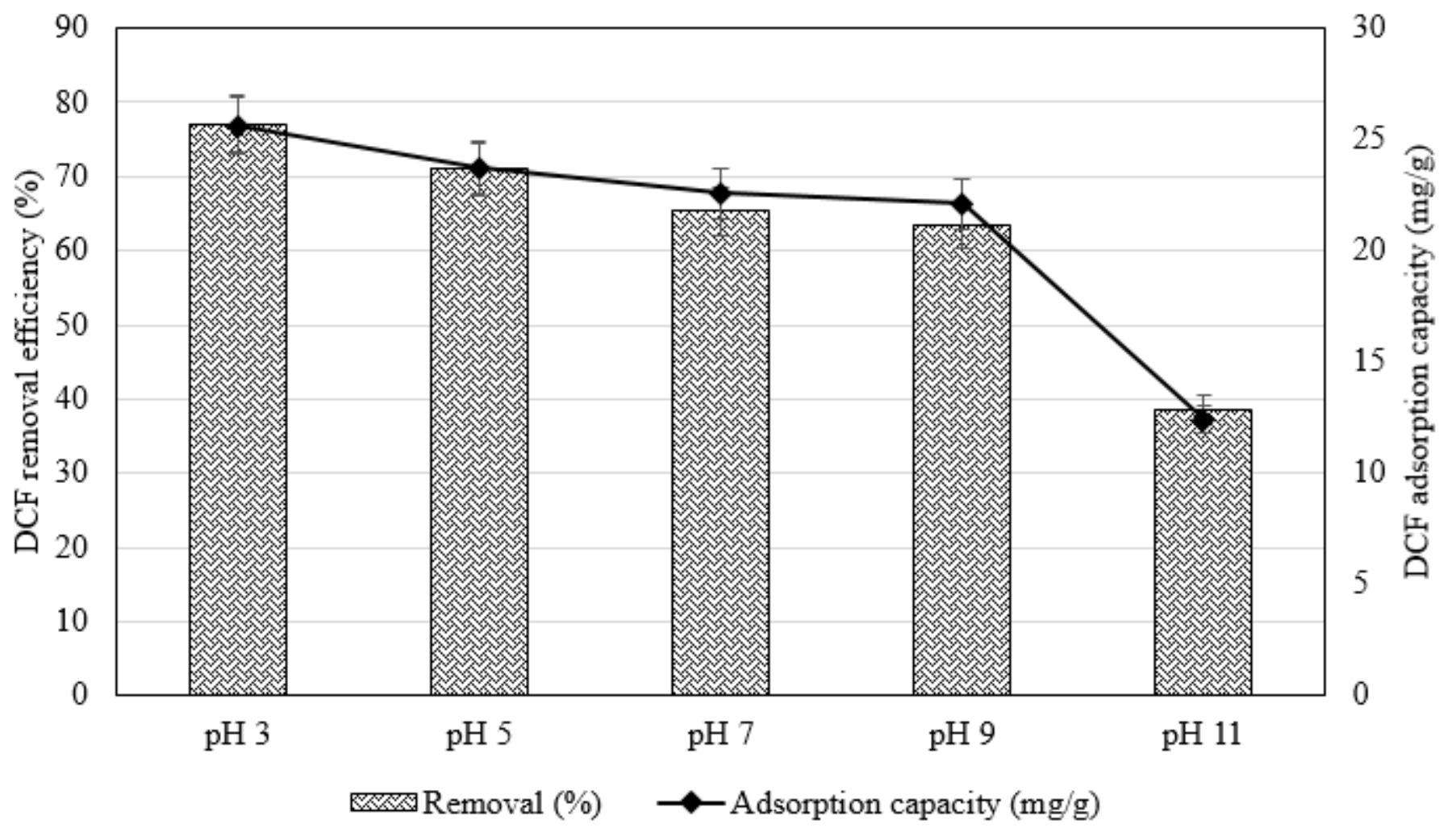

Figure 6

DCF removal efficiency and adsorption capacities of ASEC at different $\mathrm{pH}, 303 \mathrm{~K}$ and $300 \mathrm{rpm}$. 


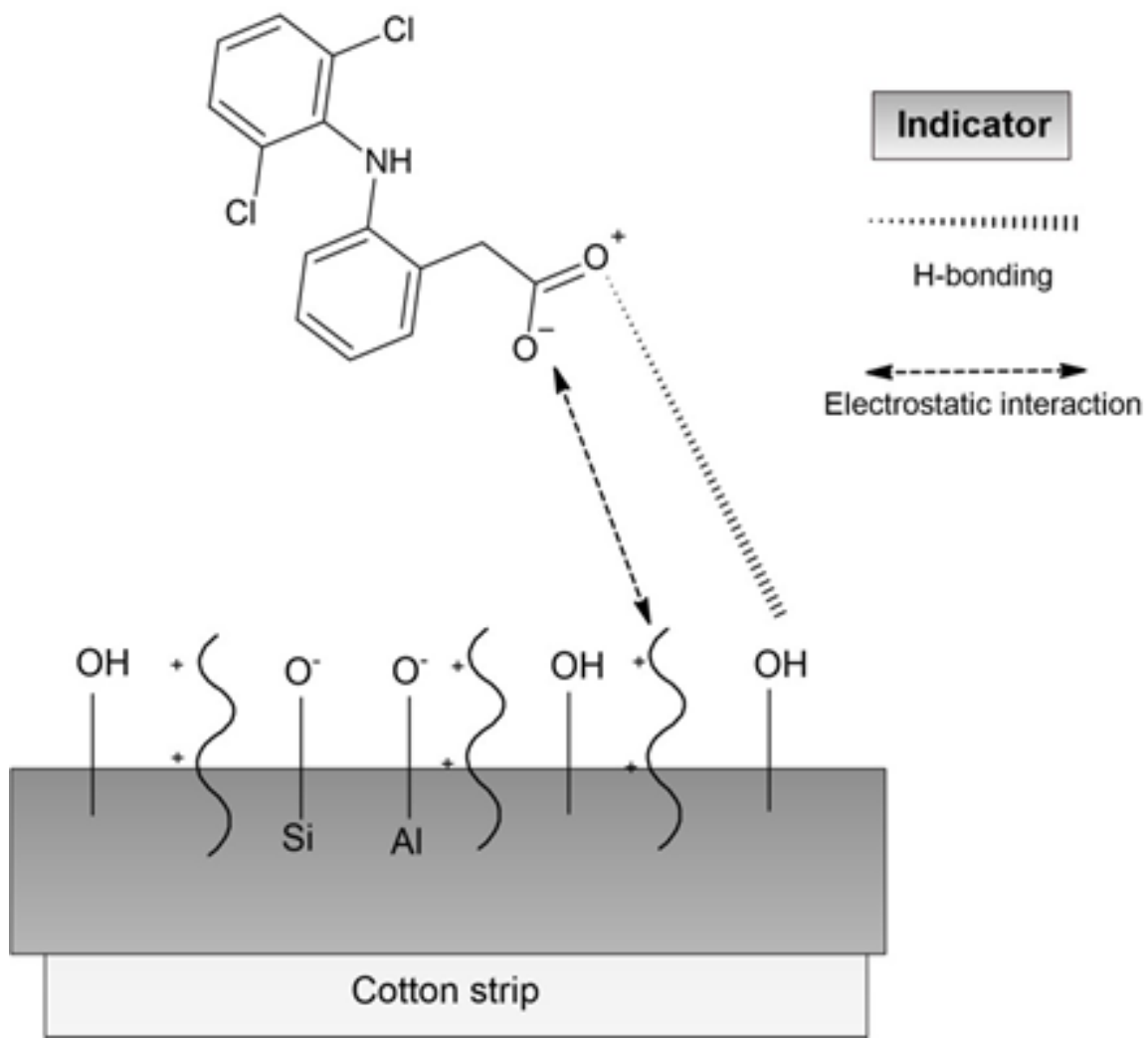

Figure 7

Interactions involved in the mechanism of adsorption of DCF on ASEC.

\section{Supplementary Files}

This is a list of supplementary files associated with this preprint. Click to download.

- Appendices.docx 